\title{
Testing procedures of the Under Sleeper Pads applied in the ballasted rail track systems
}

\author{
Cezary Kraśkiewicz ${ }^{1,}$, Wojciech Oleksiewicz ${ }^{1}$, Monika Płudowska-Zagrajek ${ }^{1}$, and Andrzej \\ Piotrowski $^{2}$ \\ ${ }^{1}$ Warsaw University of Technology, Faculty of Civil Engineering, Institute of Roads and Bridges, \\ 16 Lecha Kaczyńskiego Ave., 00-637 Warsaw, Poland \\ ${ }^{2}$ Warsaw University of Technology, Faculty of Civil Engineering, Institute of Building Engineering, \\ 16 Lecha Kaczyńskiego Ave., 00-637 Warsaw, Poland
}

\begin{abstract}
The paper describes the essential functional and operational features of the Under Sleeper Pads (USPs), used in ballasted rail track systems. The overview of appropriate test methods for determining the values of relevant parameters for the purposes of using vibro-acoustic isolators was presented, with special attention drown to the changes resulting from the introduction of the PN-EN 16730 standard in this field. Due to the given testing procedures for USPs, selected examples of the normative testing methods of the USPs' carried out at the Faculty of Civil Engineering of the Warsaw University of Technology with the results were presented.
\end{abstract}

\section{Introduction}

The Under Sleeper Pads (USP) are used in ballasted track systems to reduce the dynamic effects from the rolling stock transferred through the rails, fastening system, rail supporting structure (sleepers or turnout bearers) to the ballast [1]. They are fixed to the bottom of the sleepers or turnout bearers and cover overall or partially (in under rail section) the bottom surface of the sleeper. The broad scope of the pads thicknesses and stiffnesses allows to assemble them in different kinds of ballasted track structures, among wide range of axles loads and maximum speeds. The criteria for the selection of specific type of the Under Sleeper Pads are the limit value of the rail deflection and natural frequency of the object, which should be protected from the negative effects of vibration from rail traffic.

The technical characteristics of the Under Sleeper Pads relates to the technical and functional properties of materials, which are the most relevant for fulfillment of its essential functions, such as:

- Effective vibration isolation - maximum reduction in the level of impact in form of vibration and secondary noise. Also, providing protection against stray current.

\footnotetext{
* Corresponding author: c.kraskiewicz@il.pw.edu.pl
} 
- Significant reduction of the stress in ballast layer by increasing the area of contact surface between sleeper and ballast layer, and consequently improved sustainability and durability of this layer.

- Increased technical lifespan - maintaining long-term ability to fulfill functions mentioned above in real operating conditions, with maximum $20 \%$ of variability of main parameters of the states during laboratory fatigue tests conducted under extreme operating conditions.

Given the above requirements there is the need to standardize specific requirements pertaining to the properties of the Under Sleeper Pads, in order to ensure qualitative evaluation of products offered on the market and provide a basis for their selecting by the Purchaser.

\section{The physical and material properties of the Under Sleeper Pads and their test methods}

Until August 2016 in Poland in the field of examination of the Under Sleeper Pads testing procedures from German Standards [2, 3, 4] used to be applied. However, steel ballast plate type NSP (Figure 1a) characterised the structure imperfections and the dispersion of test results. Moreover, achieved test results, can not be correlated among various types of ballast plates. To avoid those problems, in the standard [5] implemented profiled, symmetrical Geometric Ballast Plate - GBP, which shape, dimensions and even type of steel were unambiguously defined (Figure 1b).

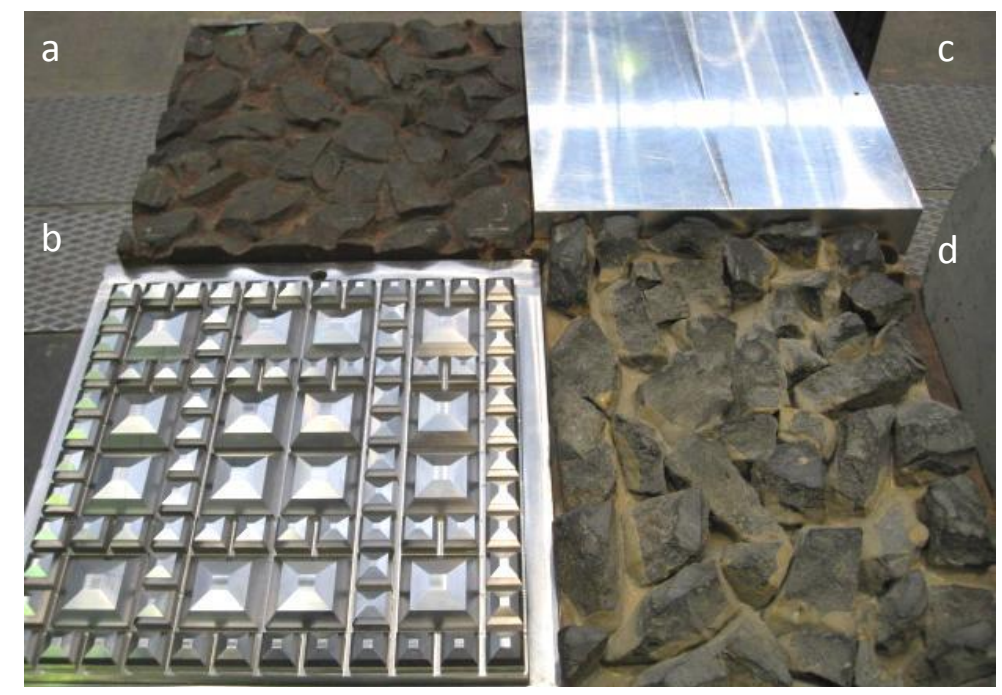

Fig. 1. Types of ballast plates used for testing the USP [6]: a) profiled, unsymmetrical plate NSP in accordance with DIN 45673-6 [3] and BN 918 145-01/02 [4]; b) profiled, symmetrical plate GBP in accordance with PN-EN 16730 [5]; c) flat plate EP; d) profiled, unsymmetrical plate TUM-P.

The testing procedures for Under Sleeper Pads are given in the standard [5], but it does not specify the required parameter values, leaving this to the rail infrastructure manager. The International Union of Railways (UIC) proposes, on the basis of own research, classification of the Under Sleeper Pads regarding to the value of static bedding modulus of the pad and the principal objectives/priority areas of applications for USPs [7]. 
Testing procedures of the USPs described in German Standards [3] are corresponding to general terms of testing procedures for other vibro-acoustic insulators in accordance with DIN 45673-1 [2].

In the further part of the article only the properties and the testing procedures of the USPs examined in the research laboratory unit at the Warsaw University of Technology in accordance with the standard PN-EN 16730 [5] will be presented.

The first stage of research is the dimensional examination of the sleeper/bearer with mounted Under Sleeper Pad. The appropriateness of the applied pad on the sleeper bottom surface - symetry of the position, the distance from the edge of the sleeper (within $5-15$ $\mathrm{mm}$ ) [1] and adhesion in the whole surface between the sleeper and the pad. The strength tests can be conducted only after finishing this stage.

\subsection{Bond strength (of pull-out)}

The Under Sleeper Pad as the element conected in a permanent way to the sleeper or bearer, must have a guarantee of proper bond strenght, so that the pad will not detache from the sleeper/bearer during transportation, handling or exploitation.

Dimensional diagram of the location of pull-out test on USP is shown in Figure 2a. The pretensioned prestressed concrete sleepers type PS-94 with the Under Sleeper Pad after the bond strength testing is shown in Figures $2 \mathrm{~b}, 3 \mathrm{a}$ and $3 \mathrm{~b}$.

a)

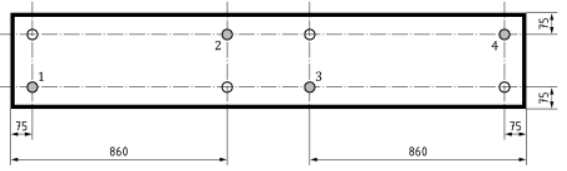

b)

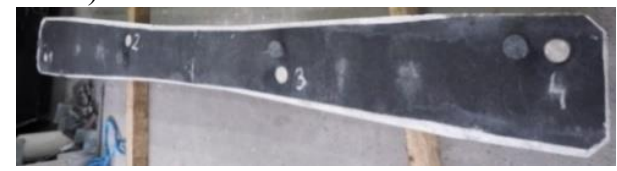

Fig. 2. Concrete sleeper with the location of pull-out test with accordance with PN-EN 16730 [5]: a) dimensional diagram of the location of measurement points; b) concrete sleeper after pull-out test.

a)

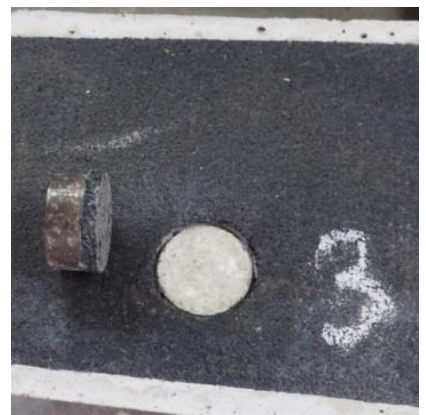

b)

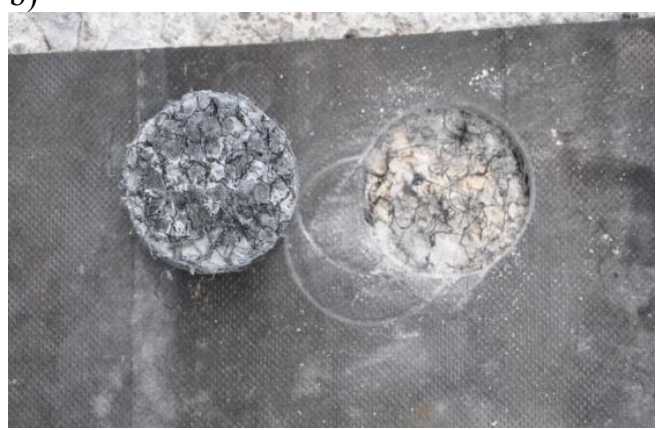

Fig. 3. The pull-out test according to PN-EN 16730 [5]: a) the test area detaches from the concrete body. Rapture at the junction of geosynthetics and elastomeric material of the USP (type of damage $\mathrm{B} / \mathrm{C}$ ); b) rapture at the junction of geosynthetics of the USP and concrete surface of the sleeper (type of damage $\mathrm{B}$ ).

\subsection{Static and dynamic bedding modulus of the Under Sleeper Pad}

Static and dynamic bedding modulus determine effectiveness of dumping vibrations transmission to the environment $[8,9,10,11,12,13,14]$. It should be noted that the Under Sleeper Pads with very low value of bedding modulus give in greater sheer deflection of rail and railway track. The value of the static and dynamic bedding modulus is defined for 
resilient mats for linear and continuous support. It includes a wide range of values from $0,02 \mathrm{~N} / \mathrm{mm}^{3}$ to $\sim 0,35 \mathrm{~N} / \mathrm{mm}^{3}$, depending on type and structure of the material, thickness of the pad, load value in which bedding modulus is defined and load frequency for dynamic modulus.

For the static and dynamic bedding modulus testing procedure three samples, each measuring $250 \mathrm{~mm} \times 250 \mathrm{~mm} \times$ thickness of the pad (Figure 4) or $250 \mathrm{~mm} \times 250 \mathrm{~mm} \times$ thickness of the pad mounted to the concrete block (Figure 5, 6), are used.

a)

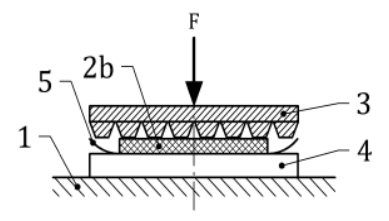

b)

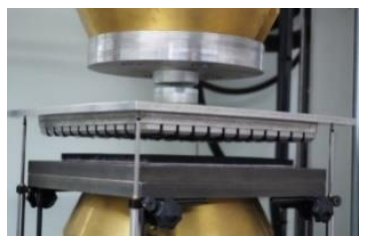

c)

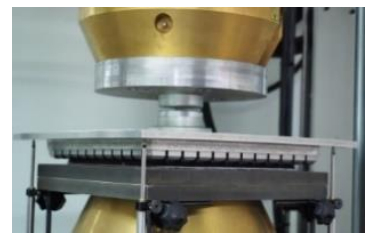

Fig. 4. The testing procedure of the static and dynamic bedding modulus of the USP according to the PN-EN 16730 [5]: a) test arrangement (key: 1 - non-deformable support; $2 \mathrm{~b}$ - USP alone; 3 geometric ballast plate in contact with the USP; 4 - load plate; 5 - abrasive cloth); b) the USP, based on the granulated rubber, before testing; c) the USP, based on the granulated rubber, under the maximum static load (maximum sheer deflection of the sample).

a)

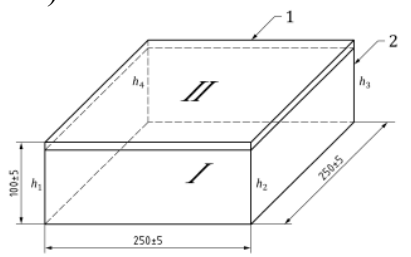

b)

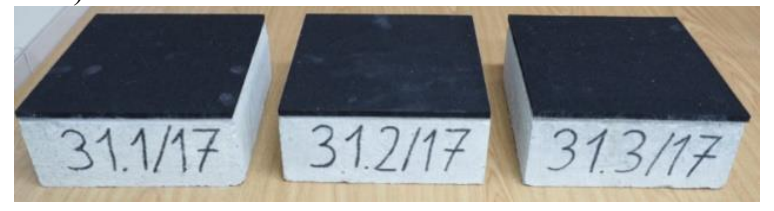

Fig. 5. Samples of the Under Sleeper Pads fixed to the concrete cubes, each measuring $250 \mathrm{~mm} \times 250$ $\mathrm{mm} \times 100 \mathrm{~mm}$ thick for the static and dynamic bedding modulus testing procedure: a) dimensional diagram of the sample with tolerances; b) samples of the Under Sleeper Pads $9 \mathrm{~mm}$ thick, based on the granulated rubber and fixed to concrete block before testing.

a)

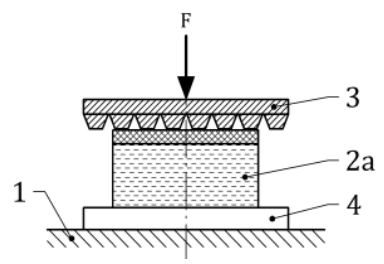

b)

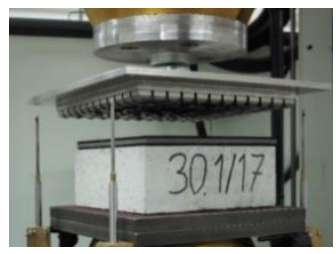

c)

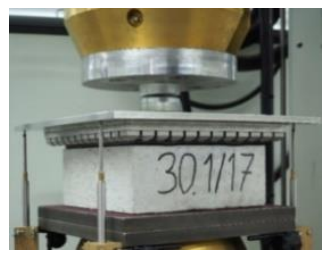

Fig. 6. The testing procedure of the static and dynamic bedding modulus of the USP on concrete block according to the PN-EN 16730 [5]: a) test arrangement (key: 1 - non-deformable support; $2 \mathrm{~b}$ USP on concrete block; 3 - geometric ballast plate in contact with the USP; 4 - load plate); b) the USP, based on the granulated rubber, before testing; c) the USP, based on the granulated rubber, under the maximum static load (maximum sheer deflection of the sample).

\subsubsection{Static bedding modulus of the Under Sleeper Pad}

Static bedding modulus $C_{\text {stat }}$ of the Under Sleeper Pad is a ratio towards pressure (force per surface) per unit deflection and measured under a uniaxial load. This parameter describes deflection of the rail under pressure of the stationary rolling stock and has impact on the sheer deflection of the railway track. Value of static bedding modulus is dependent on the 
pressure however it is not linear. Therefore, it is described for different range of loads depending on the application conditions of the Under Sleeper Pad e.g. tram, subway, rail. These range loads are set out according to the operational levels (maximum speed and axle loads) for four Track Categories - TC1, TC2, TC3 i TC4 [5].

Static bedding modulus diagrams obtained in conducted tests are shown in Figure 7. Two types of USP were tested in accordance with the requirements of the PN-EN 16730 Standard [5]:

- PUR7 - polyurethane-based pads with a thickness of $7 \mathrm{~mm}$;

- RUB7 and RUB9 - rubber-based pads with a thickness of $7 \mathrm{~mm}$ and $9 \mathrm{~mm}$.

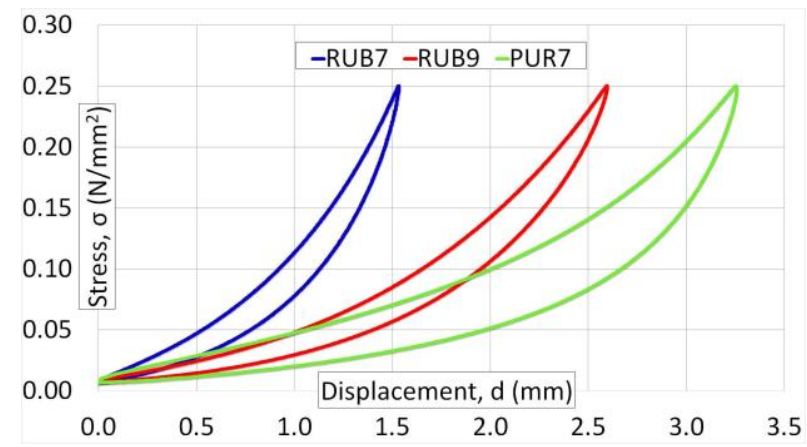

Fig. 7. Static bedding modulus of USP RUB7(29.1)/RUB9(31.1)/PUR7(30.1) according to PN-EN $16730[5]$

\subsubsection{Dynamic bedding modulus of the Under Sleeper Pad}

Dynamic bedding modulus $C_{d y n}$ of the Under Sleeper Pad is a ratio towards dynamic pressure of defined value and frequency per unit deflection and measured under a uniaxial load. The value of the dynamic bedding modulus is related not only to the loading force, as in static bedding modulus, but also to frequencies. Therefore, it should be determined under the standard pressure and frequency ranges e.g. as in PN-EN 16730 [5].

Obtained dynamic bedding modulus diagrams for tested USP are shown in Figures 8, 9. Two types of USP were tested in accordance with the requirements of the PN-EN 16730 Standard [5]:

- PUR7 - polyurethane-based pads with a thickness of $7 \mathrm{~mm}$;

- RUB7 and RUB9 - rubber-based pads with a thickness of $7 \mathrm{~mm}$ and $9 \mathrm{~mm}$.

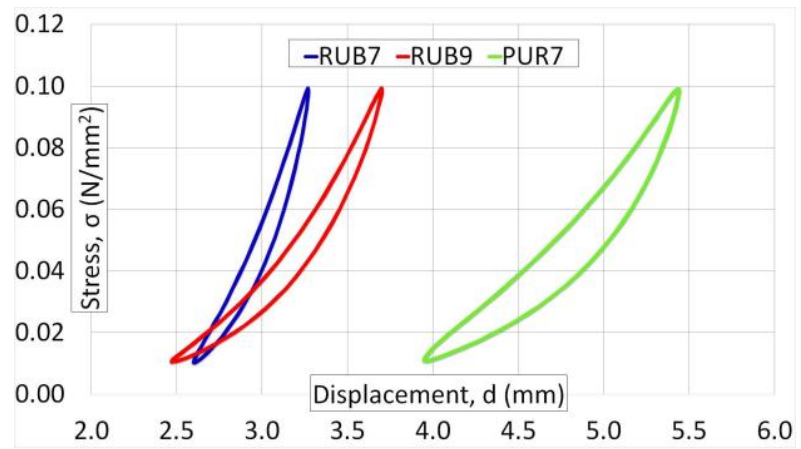

Fig. 8. Dynamic bedding modulus (5 Hz) of USP RUB7(29.1)/ RUB9(31.1)/PUR7(30.1) according to PN-EN 16730 [5]. 


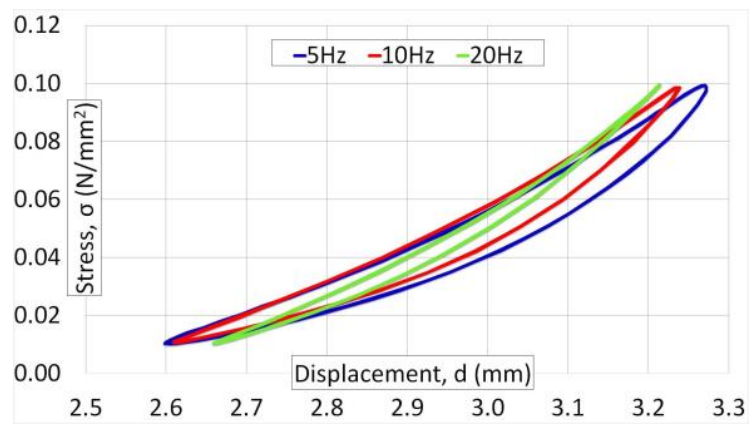

Fig. 9. Dynamic bedding modulus $(5 \mathrm{~Hz}, 10 \mathrm{~Hz}$ and $20 \mathrm{~Hz}$ ) of USP RUB7(29.1) according to PN-EN $16730[5]$.

\subsection{Dynamic stiffening ratio}

Dynamic stiffening ratio is a proportion between dynamic and static bedding modulus of the Under Sleeper Pad and defines the possibility of achieving effective vibration damping for the USPs. Because of the known property of elastomeric materials being ratedependent, it is determined for various frequencies $(5,10,20$ and $30 \mathrm{~Hz})$. Dynamic stiffening ratio is estimated as:

$$
\kappa(f)=\frac{C_{d y n(f)}}{C_{\text {stat }}}
$$

The value of the dynamic stiffening ratio is one of the factors characterizing the efficiency of vibrations dumping $[15,16]$. The closer to 1.0 the value of dynamic stiffening ratio is, the better vibration isolation properties has the test piece e.g. the Under Sleeper Pad.

\subsection{Intended working life (durability) of the Under Sleeper Pads}

The assessment of intended working life (durability) of the Under Sleeper Pad has a direct bearing on the pad damping characteristics efficiency drop and is one of the most important its parameters. In case of the maintanance of the ballasted track, replacement of the pads would require major repair of the track. When choosing the Under Sleeper Pads in the design of rail track structure, fatigue strength of the pad should be taken into account. Even if other application parameters are acceptable, the lack of fatigue strength may quite fast reduce the USPs vibration damping capacity.

The durability of the Under Sleeper Pads is eveluated through fatigue strength testing and impact of the long lasting dynamic loading on the volatility of the marked parameters. The test involves a three-stage dynamic loading of the USP on concrete block. The dynamic loads exerted by pulsator changes sinusoidally with frequency to $15 \mathrm{~Hz}$ and are induced by harmonic force (from $12 \mathrm{kN}$ to $32 \mathrm{kN}$ ). They depend on:

- Range of values of the static bedding modulus of the tested Under Sleepers Pad;

- Track Category (TC);

- I, II or III loading level (I - 2000 cycles; II - 2000 cycles; III - to the total number of 3 million cycles).

Positive evaluation of the durability of the Under Sleeper Pad covers the lack of visually inspected damages (perforation, cracking or other damage) and to determine on the basis of the changes of the static and lower frequency dynamic bedding modulus at $5 \mathrm{~Hz}$. 
The standard PN-EN 16730 [5] allows two variants of the UPS fatigue testing procedure. First one - with application of the steel ballast box instead of the geometric ballast plate (Figure 10). Second one - with the application of the geometric ballast plate instead of steel balast box (Figure 11).

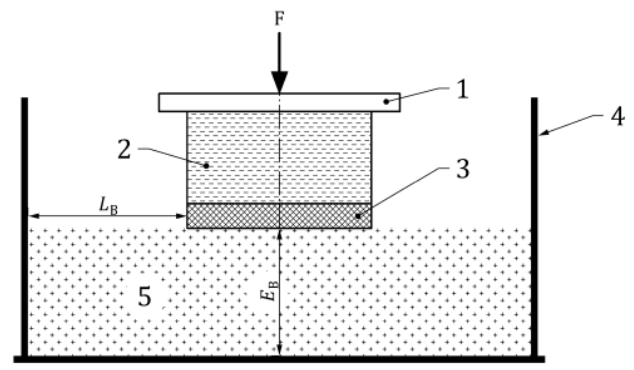

Fig. 10. The USP fatigue test arrangement. Key: 1 - load plate, 2 - concrete block, 3 - USP, 4 - nondeformable, steel ballast box, 5 - ballast (LB $\geq 200 \mathrm{~mm}, \mathrm{~EB} \geq 200 \mathrm{~mm}$ ) [5].

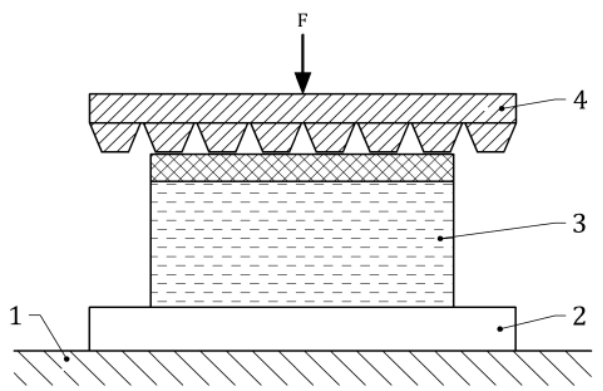

Fig. 11. The USP fatigue test arrangement. Key: 1 - non-deformable support, 2 - steel plate, 3 - the USP on concrete block, 4 - geometric ballast plate [5].

\subsection{Severe environmental conditions resistance}

Water penetration through the ballast layer has a devastating impact on the pads material. Moreover, taking into account climate and temperatures in Poland, evaluation the Under Sleeper Pads for resistance against water, frost resistance and withstanding high temperatures is definitely reasonable.

The testing procedure includes immersion the concrete block with USP in water for $24 \mathrm{~h}$ with temperature $(23 \pm 5){ }^{\circ} \mathrm{C}$. Then it is removed from the water and placed in a climatic chamber for 7 cycles of $24 \mathrm{~h}$ of the following scheme: freezing the sample to the temperature $-15{ }^{\circ} \mathrm{C}$ per $4 \mathrm{~h}$ and leaving it for the next $8 \mathrm{~h}$, after that in the next $4 \mathrm{~h}$ the sample's temperature is raised to $+40^{\circ} \mathrm{C}$, and again left in these conditions for the next $8 \mathrm{~h}$. It should be noted, that this testing procedure differ from the extreme rail temperatures with a range between $-30{ }^{\circ} \mathrm{C}$ and $+60{ }^{\circ} \mathrm{C}$, but it is reasonable by the location of the Under Sleeper Pad in the ballast layer.

Between 1 week (minimum) and 2 weeks (maximum) after the end of the testing procedure of the effect of severe environmental conditions of USP on concrete block the following tests should be done:

- measuring the static and low frequency dynamic bedding modulus at $5 \mathrm{~Hz}$;

- minimum 3 pull-out tests (after bedding modulus test);

- visual inspection of the USP in order to look for evidence of damage (assessment of evidence of perforation, cracking or other damage). 


\section{Conclusions}

The Under Sleeper Pads as components used to limit the negative effects (vibration and noise) generated by rail traffic and increase durability of the rail track structure, with further advances in engineering and material engineering, will find an increasingly widespread use in rail track structure. In order to meet their objectives, the most impostant properties of the USPs, such as static and dynamic bedding modulus, fatigue strength and bond strength to the bottom surface of the sleeper should be tested and evaluated.

Moreover, there is evident need for making provision for the new Guidelines of the basic requirements for the Under Sleeper Pads and systems used for vibration isolation, to ensure it's durability and the efficiency in vibration dumping.

\section{References}

1. C. Kraśkiewicz, W. Oleksiewicz, A. Zbiciak, Archives of Institute of Civil Engineering 25, 221-243 (2017)

2. DIN 45673-1:2010-08 Mechanical vibration. Resilient elements used in railway tracks. Part 1: Terms and definitions, classification, test procedures

3. DIN 45673-6:2010-08 Mechanical vibration. Resilient elements used in railway tracks. Part 6: Laboratory test procedures for under-sleeper pads of concrete sleepers

4. Bahn-Norm BN 918 145-01/02 Spannbetonschwellen mit elastischer Sohle. Teil 1: Elastische Swellensohle. Teil 2: Verbundsystem Spannbetonschwellen-elastische Schwellensohle. Deutsche Bahn (2004)

5. PN-EN 16730:2016-08 Railway applications - Track - Concrete sleepers and bearers with under sleeper pads

6. D. L. Iliev, Technical University of Munich (2012)

7. F. Auer, R. Potvin, UIC (2013)

8. C. Kraśkiewicz, C. Lipko, M. Płudowska, W. Oleksiewicz, A. Zbiciak, Procedia Engineering 153, 317-324 (2016)

9. A. Zbiciak, C. Kraśkiewicz, C. Lipko, W. Oleksiewicz, IPICSE-2016, MATEC Web of Conferences 86, 01015 (2016)

10. A. Zbiciak, C. Kraśkiewicz, W. Oleksiewicz, M. Płudowska-Zagrajek, C. Lipko, XXVI R-S-P Seminar 2017, Theoretical Foundation of Civil Engineering, MATEC Web of Conferences 117, 00090 (2017)

11. R. G. Wettschureck, U. J. Kurze, ACUSTICA 58, 177-182 (1985)

12. R. G. Wettschureck, DAGA 87, 217-220 (1987)

13. R. G. Wettschureck, M. Heim, S. Mühlbachler, Proceedings Inter-noise 97, 577-580 (1997)

14. M. Butorina, N. Minina, P. Ivanov, A. Petryaev, Procedia Engineering 189, 352-359 (2017)

15. P. Carels, A. Zamaro, Infrastruktura Transportu, 4 (2008)

16. P. Carels, Joint Baltic-Nordic Acoustic Meeting 2012, 1-16 (2012) 